\title{
Synthesis
}

\section{Conceptualizing, Observing, and Influencing Social-Ecological Transitions}

\author{
$\underline{\text { Marina Fischer-Kowalski }}^{1}$ and $\underline{\text { Jan Rotmans }}^{2}$
}

\begin{abstract}
This article creates a meeting ground between two distinct and fairly elaborate research traditions dealing with social "transitions": the Dutch societal transitions management approach, and the Viennese sociometabolic transitions approach. Sharing a similar understanding of sustainability transitions - namely as major transformational changes of system characteristics-and a background epistemology of complex systems, autopoeisis, and evolutionary mechanisms, they address the subject from different angles: one approach asks how transformative changes happen and what they look like, and the other approach tries answer the question of how to bring them about. The Viennese approach is almost exclusively analytical and deals with a macro ("landscape") level of human history with a time scale of decades to centuries; the Dutch approach is based on intervention experiences and deals with a shorter time frame (decades) of micro-meso-macro levels of industrial societies. From both their respective angles, they contribute to some of the key questions of sustainability research, namely: how can a transformative change toward sustainability be distinguished from other types of social change? By which mechanisms can obstacles, path dependencies, and adverse interests be overcome? And what are the key persistent problems that call for such a transition?
\end{abstract}

Key Words: social metabolism; sociometabolic regimes; transition management

\section{INTRODUCTION}

Here, we compare two different approaches to transitions of societal or socioecological systems. We start off with a broad introduction to the two approaches, describing the overall scientific claim and worldviews they share, relative to othersimilar and dissimilar-approaches. We then specify three key dimensions of intercomparison: (1) time frame and ideas about directionality of time, (2) how to deal with different functional and spatial scales, and what scale interactions matter, and (3) the patterns by which systems and actors interrelate. In the following sections, we present first the Viennese and then the Dutch approaches in more detail. In conclusion, we revisit what both approaches may be able to achieve, using the distinctions developed in the introduction for classification.

The approach of the social ecology group in Vienna is mainly academic in the sense of focusing on understanding and on the analysis of contemporary and historical phenomena of radical change in societies linked to change in their relations to the environment. The approach of the Dutch scientific network on transitions (KSI) is more practical in scope. It is centered on the concept of transition management, trying to drive system innovations, $i$. e., technological, economic, sociocultural, and institutional changes. Both approaches conceive of transitions in the sense of transformative change of present-day societies-possibly toward more sustainable solutions. Thus, they belong to the family of theories of social or socioecological change that oppose the mainstream idea that "change is incremental, generally linear, predictable and even controllable" (Stockholm Resilience Centre 2008:5) and derive from Buzz Holling's (1973) ideas of complexity, multiple stable states, and evolution as a model for management. But both focus less on local or regional ecosystems as a challenge to management, and more on the dynamics of socioeconomic systems themselves, 
the impact they have on ecosystems, and how this changes or could be changed over time.

The Viennese approach can be viewed as an increasingly mature theoretical outcome of a series of research projects using a common conceptual and methodological framework (the theoretical framework of social metabolism and the material and energy flow analysis (MEFA) methodology (see below and in more detail Haberl et al. (2004)). It has been applied globally, at the levels of nation states and of local communities, in fully industrialized and developing countries from various world regions, and in historical case studies across centuries (Fischer-Kowalski and Haberl 2007). Although, for the contemporary applications, the research usually involved some stakeholders and contributed to capacity building on their part toward finding more sustainable solutions, the core of the projects consisted in generating scientific insight. Very powerful stakeholders were rarely involved, and they almost never commissioned the research to promote change themselves.

In contrast, the Dutch transition management approach gained its momentum from a strong political trend toward achieving sustainability transitions in the Netherlands. At the national level in the Netherlands, six ministries are experimenting with transition trajectories, among which the energy transition led by the Ministry of Economic Affairs is the most prestigious and most advanced. For a more detailed description of the energy transition process in the Netherlands, the reader is referred to Kern and Smith (2007), Smith and Kern (2007), and Kemp and Loorbach (2005). Also, at the regional level, there are quite a few transition processes in progress, as described in Loorbach (2007). In terms of management, they are at a rather early stage. At the local level, numerous transition experiments have been initiated in niches that are part of the testing grounds in the fields of sustainable agriculture, mobility, construction, energy, spatial planning, and health care. Outside the Netherlands, interest in transition processes is growing, e.g., in the UK, Germany, Austria, Finland, and-most concretely-Belgium, where two transition processes are being attempted at the national level, one on waste management and one on sustainable housing and construction in Flanders.

As Berkhout et al. (2004) have rightly acknowledged, the term transition is often used as an umbrella term for a multiplicity of phenomena and requires a clearer conceptual definition. Both approaches under discussion here have attempted such a conceptual clarification, each in its own way. These conceptual clarifications contain the following components. The first, still very general, is temporal and consists of a formal model of a sequence of stages or phases. The conceptualization of these phases is shared by the two approaches. In an ideal typical manner, the transition in time is described as a sequence of alternating phases: (i) the "predevelopment phase" from a dynamic state of equilibrium in which the status quo of the system changes in the background, but these changes are not visible; (ii) the "take-off phase," the actual point of ignition after which the process of structural change picks up momentum; (iii) the "acceleration phase" in which structural changes become obvious; and (iv) the "stabilization phase" where a new dynamic state of equilibrium is achieved (Rotmans et al. 2001). The ideal typical manifestation of these alternating phases is the so-called S-curve, but other manifestations in time are also possible, such as lock-in situations or system collapse. There is a shared understanding that there is no linear, incremental path that leads from one state to another, but rather a possibly chaotic and dynamic interim process.

One has to be aware, however, that this perspective is extremely sensitive to the choice of scale. From a wider perspective, it appears as a continuous process, progressing almost linearly across space. But from a closer perspective, it appears as a whimsical, sharply fluctuating process. This leads to the insight that transition theories and theories based on the assumption of gradualism do not necessarily contradict each other. One type of process may well be "nested" within the other.

Behind this multi-phase conceptualization lies the notion of directionality of time. Various mechanisms behind this directionality of time may be distinguished. It can either imply consecutive stages of a "developmental" type (like Herbert Spencer's (1876) notion of evolution, or Marxist historical materialism (Engels 1968, Marx 1976, Foster 2000)), or it may follow a Darwinian type of evolutionary theory by assuming the future to be contingent upon the past but principally unpredictable. In the first case, when a developmental mind model is employed, stage II follows with some kind of necessity from stage I and is, as a rule, considered superior, more "mature." The progress toward this more mature 
stage can be accelerated or delayed. If the process of maturing is severely impeded or prevented altogether, some unhealthy, handicapped state or even decay of the whole system will ensue. In the second case, when either a more Darwinian evolutionary model or unspecified, open-ended change processes are assumed, the task of intervening in transition processes becomes more complex; it also encompasses the choice of direction. In reference to Boulding (1970), the Dutch approach distinguishes the following dimensions: (i) teleological vs. emergent, (ii) degree of coordination (from high to low), and (iii) level of aggregation (high vs. low). In this way, it can identify eight types of transitions: from emergent, hardly coordinated, and highly aggregated transitions, such as the internet revolution, to teleological, highly coordinated, and slightly aggregated transitions, such as the transition from coal to gas. Current transitions in the fields of energy, agriculture, mobility, water, and construction, which are part of Dutch transition policies, differ in certain key dimensions according to this typology. They are similar with respect to the degree of coordination (high, with much interference from the government) and the level of aggregation (high, $i$. e., geared toward an integral approach at the domain or sector level), but not with regard to the degree of specific focus. The energy transition appears to be more targeted than the mobility transition and also more targeted than the agricultural transition.

The second important conceptual component characterizing "transitions" concerns the interaction across multiple scales or levels. According to the Viennese approach, the key to a transition is located in a society's energy system, and the impact of changes in this energy system is different across scale levels. Depending on the reasons and the speed of an energy transition, parts of the system may at a certain point in time be under different energy regimes (e.g., urban industrialized centers may coexist with traditional agricultural communities, or industrializing core countries with agrarian colonies that are deliberately kept in that state), and the tensions that arise from this have an impact on the overall course of the transition (Sieferle et al. 2006, Krausmann et al. 2008). How this evolves is fairly case specific: no general theoretical guidelines have been developed. The Dutch group, on the other hand, describes a transition systematically as interference of processes at three different scale levels: macro-meso-micro (Rip and
Kemp 1998). The scale levels are interpreted as functional scale levels, not directly as spatial or geographical scale levels. They represent functional relationships among actors, structures, and working practices that are closely interwoven (Rotmans 2005). The higher the scale level the more aggregated the components and the relationships and the slower the dynamics are among these actors, structures, and working practices. The approach assumes that the transition dynamics do not start in one place but at different locations at different scale levels. Only when these dynamics modulate (have a similar direction), can a scaling-up effect and thus a spiral effect emerge as a necessary condition for achieving a transition. Both approaches see a crucial aspect of multi-level dynamics in the notion of emergence: neither can one state be deliberately transformed into the other, nor can the process be fully controlled. One deals with autopoietic processes to which orderly governance or steering cannot be applied.

The third conceptual component concerns the patterns by which transitions may come about. The Dutch approach describes the dynamics of a transition in terms of generic "patterns" resulting from a complex interplay between a dominant (or "incumbent") regime and a set of competing niches. The dynamics involve tensions between the regime and its environment (both from the landscape and niches) out of which threats may arise to the currently dominant regime. The regime may be threatened from the niche level, or from changes at the broader landscape level of economic, ecological, and cultural trends, or from internal misalignment among regime actors (Geels 2005, de Haan and Rotmans 2007). Once a threat is recognized, regime actors will mobilize resources from within the regime, and in some cases from within niches, to respond to it (Smith et al. 2005, Geels and Schot 2007). Three patterns have been identified: (i) bottom-up pattern, where niches emerge at the micro level, cluster and attack the incumbent regime, which ultimately is transformed into a new regime; (ii) squeezed paths, where niches emerge at the meso level and gradually incorporate the niche regime and evolve into a new regime; (iii) top-down pattern, where a massive, fast change in the landscape leads to a striking pressure on the regime that results in a regime change. This is not so much related to niche developments but rather to relatively fast top-down changes that profoundly impact the regime. 
The Viennese team, on the other hand, has conducted a substantial amount of research into historical and contemporary cases of transitions in order to identify their main drivers, such as population growth and density (for developing countries along the lines of Boserup (1981); for contemporary Europe, see Weisz et al. (2006)), resource and land scarcity (for the UK and Austria, see Sieferle et al. (2006)), climatic variations, or specific colonial and trade relations (Schandl and Eisenmenger 2006). The specific strength of the approach lies in its methodology to empirically describe the metabolism of social systems on various scale levels, the changes this triggers in various ecosystems, and the boundary conditions for dynamic equilibria of co-evolutionary states. But the approach remains mainly on the level of systems analysis and does not provide a guideline for potential interventions - this may be exactly the place where a meeting ground between the two approaches ought to be elaborated.

\section{THE VIENNESE SOCIOMETABOLIC TRANSITIONS APPROACH}

The point of departure for the Viennese team's analysis is not a diagnosis of a social system being stuck or being locked in a certain pattern, but a diagnosis of an ongoing, rapid, fundamental transition on a global, "landscape" level.

The environmental historian John McNeill (2000) addressed this phenomenon by the ironic title "Something new under the sun" when reviewing the 20th century. According to the statistics he assembled, there is rarely any dimension of human social life and interference with the environment that has not undergone a rapid expansion worldwide during this one century, an expansion that exceeded, sometimes by an order of magnitude, the factor 5 growth of the human population, which is substantial in itself. Taking John McNeill's reconstruction of the 20th century seriously, the world is neither in a stable status quo, nor in the position of a new equilibrium. Even if the term "dynamic equilibrium" is used very liberally, an ongoing physical explosion in limited space cannot be described as an equilibrium. It is also hard to believe the world to be still in a take-off phase, if all of the past century was marked by such tremendous changes. It appears most likely that it is within an acceleration phase, in the middle of a transition. How far this acceleration still has to go is the question. It is highly improbable that the sociometabolic regime in place now will continue for, say, another 200 years. The ongoing transition is bound to lead to some new, as yet unknown, state.

One arrives at such a storyline on transition from a global perspective and the vantage point of environmental history. On another time scale, and for another selection of variables, other events come into sight as being a transition. In the sociometabolic transition approach (Fischer-Kowalski and Haberl 2007), a large time frame-a time frame from decades to centuries - and global interconnectedness are considered. On this scale, one cannot easily deal with actors and their deliberate efforts. What one can mainly analyze is structural change of interlinked social and natural systems, across a broad range of variables. Among these, the Viennese approach focuses on a relatively narrow set, circumscribed by a particular sociometabolic paradigm as specified below, a set of variables localized at the society-nature interface for which quantitative measurements can be reliably obtained in very different contexts. The advantage of this restraint is that one can demonstrate the interconnectedness of (some) socioeconomic changes and (some) changes in natural systems very clearly, and thereby acquire the ability to model important necessities and constraints for a sustainability transition. Such a sustainability transition is conceptualized as a transition from the present sociometabolic regime into another one, on the same level with major transitions in history, such as, for example, the "industrial revolution." The term sociometabolic regime, in the Viennese approach, is defined on a macro-a "landscape" level, as a dynamic equilibrium of a system of society-nature interaction. When the regime changes, so too does not only society and its metabolism, but also the natural systems it interacts with (Fischer-Kowalski and Haberl 2007). A regime can be characterized by the sociometabolic profile of the society involved and the concomitant modifications in natural systems that occur either as an unintended consequence (such as pollution) or as an intentional change induced by society (such as land-use patterns). "Society" is seen as a structural coupling of a communication system (Luhmann 1995) with biophysical compartments (e. g., a human population, livestock, and physical infrastructure); social metabolism serves to reproduce these biophysical compartments within a certain territory (Fischer-Kowalski and Weisz 1999). Making use of the sociological theory of 
society as an operationally closed, autopoietic system of communication rules out the possibility of conceiving of it as subsystem of an ecosystem, as often conceptualized within more natural science-based sustainability research (e.g., Berkes and Folke 1998). It allows better understanding of the often seemingly incomprehensible "incapacity" of social systems (such as the economy) to adequately perceive and deal with environmental consequences of their pursuits.

\section{Sociometabolic Regimes, Metabolic Profiles, and Transitions in World History}

If society is a hybrid, comprising an autopoietic communication system and material elements to which it is structurally coupled, then everything that affects these material elements affects society itself. This way of looking at history relates to the Marxist "materialist" tradition, but it transcends it in an ecological or co-evolutionary direction, as for example outlined by the anthropologist and historian M. Godelier. The classic reading of Marx leads to a discussion of changing "modes of appropriation of nature" through the development of new means of production, i.e., technology. Godelier's reading stresses the fact that human appropriation of nature modifies nature and this modified nature in turn stimulates social change. Godelier thus deviates from common social science by viewing nature as historically variable, not as static - and his core hypothesis attributes societies' historical dynamics to a feedback process from nature. So, according to Godelier, the dynamic force in human history is not so much the dialectics of "means of production" and "modes of production" with nature as an external element, as something to be appropriated, but is instead the very interaction between social and natural (Godelier 1986). Yetaccording to sociological systems theory - the ways in which society responds to changes in the natural environment are determined within the communication system. This communication system may be unable to generate adequate responses, responses sufficient to secure society's metabolism: then, processes in the environment, the dynamics of natural systems that society depends upon, will continue to challenge society (such as soil deterioration, climate change, epidemics) until it has changed sufficiently to be able to provide an adequate response, or until it collapses.
Society reproduces its biophysical compartments, among them the human population, by interacting with natural systems: by organizing energetic and material flows from and to the environment by means of particular technologies, and by transforming natural systems through labor and technology in specific ways to make them more useful for society's purposes. This in turn triggers intended and unintended changes in the natural environment to which societies react. Thus, societies become structurally coupled to parts of their environment so that both mutually constrain each other's future evolutionary options (Goudsblom et al. 1996). In this co-evolutionary process, idealtype "states" can be distinguished, patterns of society-nature interactions that remain in a more or less dynamic equilibrium over long periods of time ("sociometabolic regimes") and periods of transition.

For the Viennese social-ecology approach, sociometabolic regimes in world history correspond to what many authors, using different terms, have addressed as human modes of subsistence (Gellner 1988, Boyden 1992, Diamond 1997, Sieferle 1997). The transitions between these modes of subsistence have often been called "revolutions," namely the Neolithic revolution (the transition from huntergatherer to agrarian society) and the Industrial revolution (the transition from agrarian to industrial society). Why did particular sociometabolic regimes not last forever or, in other words, why were they not sustainable? Why was there, for example, a transition from the hunter-gatherer to agrarian mode? And why, after roughly 10000 years of agrarian societies, did a transition we call the Industrial Revolution begin, leading to another mode that is still so dynamic that we find it hard to look at it as a mode, as a sociometabolic regime of some dynamic stability, at all? And in what relation to all this is a possible future sociometabolic regime we might head for as "sustainable"? These are grand questions indeed, and they are dealt with by this approach to put the sustainability transition in perspective.

Looking back at history, reference is made to the work of the environmental historian Sieferle (2003). According to him, hunters and gatherers sustain themselves through passive solar-energy utilization, that is, their social-energy metabolism depends on the existing density of solar radiation and its transformation into plant biomass - they do not 
deliberately intervene in this transformation process. Thus, hunters and gatherers must live more or less on the resource density they find and can neither accumulate resources nor seriously pollute their environment. The only sustainability threat they pose is overexploitation of key resources. For example, there is evidence that hunter-gatherers, although they probably consumed less than $0.01 \%$ of the net primary production (NPP) of their habitat, contributed to the extinction of a significant part of the Pleistocene mega fauna (i.e., of animals over 10 $\mathrm{kg}$ body mass, which are most suitable for hunting and were, therefore, an important part of the resource base). Although the issue is highly controversial, it is a case for bringing the huntergatherer sociometabolic regime into debate, as far as sustainability is concerned. However, this sociometabolic regime could persist for several hundred thousand years.

Agrarian societies, following Sieferle, are characterized by an energy regime of "active solar energy utilization." Their solar-energy utilization is active insofar as they intervene into the solar-energy transformation process by biotechnologies and by mechanical devices. Most important is the biotechnological transformation of terrestrial ecosystems: agrarian societies clear forests, create agro-ecosystems, breed new species, and seek to extinguish other species. The core strategy is the monopolization of area (and the corresponding solar radiation) for organisms of high utility to humans. Mechanical devices (such as a sailing boat or a watermill), on the other hand, transform solar energy occurring as wind or running water into a movement that can be used by humans. Agrarian societies seem to have always, more or less successfully, struggled with keeping the delicate balance between population growth, agricultural technology, labor force needed to maintain the productivity of agro-ecosystems, and the maintenance of soil fertility. Agrarian civilizations were always at risk, most often from a combination of technological and political dependencies and the fluctuations of natural systems. Not only did Ancient Mesopotamians gradually degrade their soils by irrigation techniques, forcing peasants at first to give up wheat cultivation for the more salttolerant barley, and later to abandon cultivation altogether, but also medieval peasants in the Netherlands lost their fight against sand dunes. Nevertheless, the agrarian sociometabolic regime persisted in many parts of the world for several thousand years and still persists.
The presently dominant industrial sociometabolic regime dates back no more than 300 years and is based on the use of fossil fuels. Its sustainability seems limited not only by the limitations of its energy resource base, but also by the transformations it triggers globally in various lifesustaining natural systems. Today, global change research provides ample evidence that major human-induced changes can be found on any spatial scale, from local to global, and transform the earth's system at an increasing pace (Turner et al. 1990, Schellnhuber 1999). So this sociometabolic regime is bound to change as it erodes its natural base. In this situation, sustainability may be about guiding this transition within a corridor of acceptable quality of life, for present and future human generations.

The social-metabolism approach is attractive as it allows definition of the biophysical structures of societies in a way that is compatible with the compartment models usually used in systems ecology (Haberl 2001). That is, the metabolism approach allows looking at biophysical aspects of a society as if it were an ecosystem compartment: its material stocks as well as the flows between the biophysical structures of society and the rest of the natural world. So, basically the same concepts and methods can be used to deal with social and natural systems.

The stocks and flows listed in Table 1 deliver a biophysical description of any society in analog to an ecosystem, and the interrelations between stocks and flows are - within a certain range - determined by natural processes. By a description of these parameters, any society can be "grounded" within natural systems. Anthropology, for example, has a long tradition of analyzing the relationship between simple societies and their natural environment by tracking energy flows (e.g., White 1943, Rappaport 1971). For complex modern societies, such an approach can be traced back to the early 1970s (Ayres and Kneese 1969, Boulding 1973). According to these authors, that biophysical description can be directly linked to the economy. In particular, MEFA seeks to analyze biophysical aspects of society in a way that is compatible with the most common and powerful tool for societal self-observation, the system of national accounts. By means of this "double compatibility," social metabolism establishes a link between socioeconomic variables on the one hand, and biophysical patterns and processes on the other hand. In the language of the Stockholm-centered resilience approach (e.g., 
Gunderson and Holling 2002), one might say the potential to maintain a certain metabolism is key to the resilience of a particular social-ecological system.

Another set of relations listed in Table 1 centers around territory and land use-one of the most important socioeconomic pressures on the environment and a driving force of global change (Vitousek 1992, Meyer and Turner 1994). This set of relations comes under the heading of "colonization of terrestrial ecosystems" (FischerKowalski and Haberl 1997, Haberl et al. 2001, Krausmann and Haberl 2002). Whereas socioeconomic metabolism refers to the exchange of energy and matter between social and natural systems, colonization refers to society's deliberate interventions into natural systems in order to create and maintain a state of the natural system that renders it more useful socially (Fischer-Kowalski and Weisz 1999). Thus, colonization refers mainly to human labor and to the information, technologies, and skills involved in making labor effective. This theoretical concept has within the MEFA approach become operational in describing land use. Socioeconomic land use can be related to changes in ecosystem patterns and processes. The impact of land use can be measured by comparing ecosystem patterns and processes that would be expected without human intervention with those observable in the presence of interventions. An example of this approach is the calculation of the "human appropriation of net primary production," or HANPP (Vitousek et al. 1986, Haberl et al. 2007).

By using the MEFA approach, the Viennese team was able to reconstruct the metabolic profiles of a large number of social systems at various scales, and across long time series. As a result, the characteristic metabolic profiles of regimes can be identified (see Table 2), and this allows a reframing of the sustainability transition problem. It becomes apparent that in history thus far, transitions between one sociometabolic regime and the next were associated with a substantial increase in metabolic rates (in terms of joules and tons of socioeconomic input per capita population). This increase was three- to fivefold in the case of the hunter-gatherer transition to agriculture (Fischer-Kowalski and Haberl 1997), and was again (and is) three- to fivefold in the agrarian-industrial transition (see Table 2). On the global level today, about two-thirds of the world's population live more or less by a metabolic profile of the agrarian societies in the past, and they are rapidly about to change that toward an industrial profile (see empirically in Krausmann et al. (2008)). For the industrial countries, it is very clear that a next historical transition cannot follow the old pathway of multiplying energy and materials use once again. If there is to be a meaning to a sustainability transition, it should imply a substantial reduction in energy and material flows per capita - and this would also have to demonstrate a pathway for the developing countries to pursue. It is interesting to note that in many of the most highly developed countries of the world (such as the EU 15 states and Japan), despite continuing economic growth, metabolic rates have ceased to grow (Eurostat 2005). This could be interpreted as a sign of a beginning transition, but perhaps it is occurring only as a consequence of externalization of energetically and materially intensive production processes to the developing world via trade.

Thus, the Viennese approach seems to be able to outline the problem and also some of the quantities to deal with. But, for translation into policy, it offers at best some theoretical guidelines and some targets. This is exactly where the Dutch "transitions management" approach comes in. This much more pragmatic, action-oriented research tradition has evolved to deal with those "persistent problems" ingrained in what the Viennese call a sociometabolic regime. Can their notion of transition be reconciled with and fruitfully related to the Viennese social-metabolic approach referred to above?

\section{THE DUTCH TRANSITION MANAGEMENT APPROACH}

\section{A Complex Systems Approach for Governing Transitions}

The starting point of the Dutch approach is the persistent problems whose symptoms are becoming more and more apparent. Persistent problems are the superlative form of what Rittel and Webber (Rittel and Webber 1973) refer to as "wicked problems." They are complex because they are deeply embedded in our societal structures, uncertain due to the hardly reducible structural uncertainty they include, difficult to manage with a variety of actors with diverse interests involved, and hard to grasp in the sense that they are difficult to interpret and ill structured. An example of a persistent problem is the energy problem with 
Table 1. Biophysical dimensions of social systems.

\begin{tabular}{ll}
\hline \hline Stocks & Flows \\
\hline Human population & $\begin{array}{l}\text { Natural reproduction } \\
\text { Migration } \\
\text { Living time-labor time }\end{array}$ \\
& $\begin{array}{l}\text { Energy input-output } \\
\text { Other biophysical stocks (livestock, infrastructure, durables) }\end{array}$ \\
$\begin{array}{ll}\text { Material input-output } \\
\text { Territory }\end{array}$ & $\begin{array}{l}\text { Appropriation of net primary production } \\
\text { Water use }\end{array}$ \\
\hline
\end{tabular}

anthropogenic climate change as manifestation, which cannot be solved using only current policies. Existing policies are necessary but not sufficient, much more is needed (Ministry of Housing, Spatial Planning and Environment 2001).

Persistent problems require transitions: fundamental changes in the structure, culture, and practices of societal systems (Rotmans and Loorbach 2008). By structure, we mean physical infrastructure (physical stocks and flows), economic infrastructure (market, consumption, production), and institutions (rules, regulations, collective actors such as organizations, and individual actors). By culture, we mean the collective set of values, norms, perspective (in terms of coherent, shared orientation), and paradigm (in terms of way of defining problems and solutions). And by practices we mean, collectively, production routines, behavior, ways of handling, and implementation at the individual level, including self-reflection and reflexive dialog. Transitions cannot be steered in command-and-control terms, because they are too complex phenomena with many uncertainties and surprises. However, transitions can be influenced and guided, in terms of influencing the speed and direction of these processes. The latter we call transition management, which will be described below (Loorbach and Rotmans 2006).

Within the context of the Dutch Knowledge Network on System Innovations and Transitions (KSI), we use complex systems theory to study the dynamics of societal systems in order to derive a collection of basic guidelines that can be used to direct societal systems. The very idea is that a better insight into the functioning of complex societal systems provides insight into the possibilities of directing these systems. Both angles will be briefly described below.

Complex adaptive systems are able to respond to and adjust themselves to changes in their environment. Examples of complex adaptive systems are the stock market, ant colonies, living organisms, ecosystems, cities, the human brain, business companies, political parties, and communities. Complex adaptive systems contain special objects, agents, that interact with each other and adapt themselves to other agents and changing conditions. This is why complex adaptive systems have unique features such as: "co-evolution," "emergence," and "self-organization." In the complex systems context, co-evolution means that a complex, adaptive system co-evolves with its environment, referring to interdependencies and positive feedbacks between the complex system and its environment (Mitleton-Kelly 2003). Emergence in complex system terms means the "spontaneous" formation of new structures and patterns in the system from within. And self-organization is the ability to develop a new system structure as a result of the system's internal constitution and not as a result of external management (Prigogine and Stengers 1984).

Any kind of adaptation and self-organization of complex systems involves "variation" and "selection" internal to the system that may well be external to components of that system. Most of the time complex adaptive systems are in a period of dynamic equilibrium, with ongoing variation and 
Table 2. Metabolic profiles of the agrarian and industrial socioecological regimes.

\begin{tabular}{|c|c|c|c|c|c|c|c|c|c|}
\hline & & $\begin{array}{l}\text { Agrarian } \\
\text { regime }\end{array}$ & $\begin{array}{l}\text { Industrial } \\
\text { regime }\end{array}$ & LD* & $\mathrm{DC} * *$ & $\begin{array}{l}\mathrm{EU}^{* *} \\
15\end{array}$ & $\begin{array}{l}\text { UK } \\
1750 \dagger\end{array}$ & $\begin{array}{l}\mathrm{UK} \\
1830 \dagger\end{array}$ & $\begin{array}{l}\text { UK } \\
2000 \dagger\end{array}$ \\
\hline $\begin{array}{l}\text { Population } \\
\text { density }\end{array}$ & {$\left[\mathrm{cap} / \mathrm{km}^{2}\right]$} & $30-40$ & $100-300$ & 40 & 76 & 116 & 30 & 76 & 247 \\
\hline $\begin{array}{l}\text { Energy use per } \\
\text { capita }\end{array}$ & [GJ/cap/yr] & $50-70$ & $150-400$ & 33 & 64 & 205 & 63 & 68 & 189 \\
\hline $\begin{array}{l}\text { Energy use per } \\
\text { unit area }\end{array}$ & [GJ/ha/yr] & $20-30$ & $200-600$ & 13 & 49 & 216 & 19 & 52 & 468 \\
\hline Biomass & {$[\%]$} & 95-100 & $10-30$ & 92 & 50 & 23 & 94 & 54 & 12 \\
\hline Fossil fuels & {$[\%]$} & $0-5$ & $60-80$ & 8 & 50 & 77 & 6 & 46 & 78 \\
\hline Other & {$[\%]$} & $0-5$ & $0-20$ & $\ddagger$ & $\ddagger$ & $\ddagger$ & $\ddagger$ & $\ddagger$ & 10 \\
\hline $\begin{array}{l}\text { Material use per } \\
\text { capita }\end{array}$ & [t/cap/yr] & $2-5$ & $15-25$ & 4.2 & 6.8 & 16 & 5.7 & 6.4 & 11.6 \\
\hline $\begin{array}{l}\text { Material use per } \\
\text { unit area }\end{array}$ & [t/ha/yr] & $1-2$ & $20-50$ & 1.3 & 4.8 & 18 & 1.7 & 4.9 & 28.7 \\
\hline
\end{tabular}

Source: Fischer-Kowalski et al. 2007:231.

* LD = least-developed countries.

$* * \mathrm{DC}=$ developing countries (according to UN definitions).

** EU $15=15$ member countries of the European Union.

$\dagger$ Year

$\$$ included in numbers for fossil fuels.

selection, but with selection as the predominating mechanism. External stimuli force the system to shift (across the chaotic edge) to a relatively short phase of instability and chaos (punctuated equilibria), where variation predominates. We can express system variation in terms of "diversity" and "heterogeneity." Diversity and heterogeneity are key features of complex adaptive systems: diversity of components, of relations, of systems behavior, etc. Complex adaptive systems constantly create variety, in terms of creating new components and relations, providing a source of novelty in these systems. Selection then, maintains the system in a dynamic equilibrium, by preventing variation or by pushing it in a certain direction.

In a transition, the complex adaptive system is successfully adjusted to changed internal and external circumstances and the system thus arrives at a higher order of organization and complexity. In societal systems, a small group of newcomers might build up niche regimes that are ultimately able to break down the incumbent regime and establish a new regime. In the sociotechnical literature, a regime is characterized by a set of rules (regulative, normative, and cognitive) where the unit of reference is a particular sociotechnological environment (Geels 2002). Here, we define a regime in a broader sense, with a specific societal system as a unit of reference: a conglomerate of structure (institutional setting), culture (prevailing perspective), and practices (rules, routines, and habits). The regime's cognitive, normative, and regulative institutions act to establish and reinforce stability and cohesion of societal systems, but they also limit innovation to localized, incremental improvements (Geels 2005). 
We describe the nature of transitional dynamics in terms of a generic pattern that consists of a sequence of mechanisms that result in irreversible changes in the system. A key pattern is the following: "niches" -individual technologies, practices, and actors outside or peripheral to the regime-as the loci for radical innovation (Rotmans et al. 2001, Geels 2005, Smith et al. 2005). Niches emerge and cluster, and by empowering a niche cluster, a niche regime unfolds; the niche regime becomes more powerful whereas the regime is weakening and finally the niche regime becomes dominant and takes over the incumbent regime. A pattern of mechanisms is built up, and a manifestation of such a pattern is a pathway. Underlying mechanisms are variation and selection, adaptation, emergence, clustering, empowerment, transformation, decay, and building up. Three variants of this key pattern have been distinguished (see de Haan and Rotmans 2007): (i) micro-meso pattern, where niches emerge at the micro level, cluster, and form a niche regime that attacks the incumbent regime, which ultimately is transformed into a new regime; (ii) meso-meso pattern, where niches emerge at the meso level and form a niche regime within the incumbent regime, which gradually incorporates the niche regime and evolves into a new regime; (iii) macro-meso pattern, where a massive, fast change in the landscape leads to a striking pressure on the regime that results in a regime change. This is not so much related to niche developments but rather to relatively fast top-down changes that profoundly impact the regime.

\section{Transition Management}

Based on insights from complexity theory, a number of theoretical principles have been derived for transition management. The first principle is that of "creating space for niches" in so-called transition arenas. The notion of arena originates from that part of complexity theory that indicates that a small initial change in the system may have a great impact on the system in the long run. In systems terms, we call this an emergent structure: an environment that offers some protection for a small group of agents. An emergent structure draws only a little energy from the system and has not yet been molded by the existing equilibrium, so it doesn't do much harm and is not immediately threatening to the system. The self-organizing capacity of the system generates new, dissipative structures in the form of niches. A niche is a new structure, a small core of agents, that emerges within the system and that aligns itself with a new configuration. The new alignment is often the emergent property of the system. An emergent structure is formed around niches to stimulate the further development of these niches and the emergence of niche regimes.

The "focus on frontrunners" is a key aspect of transition management. In complex system terms, frontrunners are agents with the capacity to generate dissipative structures and operate within these deviant structures. They can only do that if they are not (directly) dependent on the structure, culture, and practices of the regime. In the context of transition management, by frontrunners, we mean agents with specific abilities and qualities: creative minds, strategists, and visionaries. Transition management draws together a selective number of these frontrunners in a protected environment, an arena. In order to effectively create a new regime, agents are needed at a certain distance from that regime. However, the continuous link with the regime is important, therefore, regime agents are also needed, in particular change-inclined regime agents.

Another principle of transition management is "guided variation and selection." This is rooted in the notions of diversity and coherence within complexity theory. Diversity is required to avoid rigidity within the system. Rigidity here means reduced diversity due to selection mechanisms, which means that the system cannot respond flexibly to changes in its environment. Coherence refers to the level of interrelatedness among the entities of a complex system. In the equilibrium phase, there is continuous variation and selection but when a regime settles this becomes the dominant selection environment and thus decreases the diversity. However, a certain amount of diversity is required to explore a diversity of innovative options instead of looking for the optimal solution. Rather than selecting innovative options at too early a stage, options are kept open in order to learn about the pros and cons of available options before making a selection. Through experimentation, we can reduce some aspects of the high level of uncertainty so that it leads to better-informed decisions.

The principle of "radical change in incremental steps" is a paradox that is derived from complexity theory. Radical, structural change is needed to erode the existing deep structure (incumbent regime) of a system and ultimately dismantle it. Immediate radical change, however, would lead to maximal resistance from the deep structure, which cannot 
adjust to a too fast, radical change. Abrupt forcing of the system would disrupt the system and create a backlash in the system because of its resilience. Incremental change allows the system to adjust to the new circumstances and build up new structures that align with the new configuration. Incremental, however, does not mean gradual development. Transitional change is characterized by periods of relatively drastic, sudden, and radical changes, also known as "punctuated equilibria" (Gould and Eldredge 1977, Gersick 1991). Radical change in incremental steps, thus, implies that the system heads in a new direction toward new attractors, but in small steps.

"Empowering niches" is an important principle of transition management. By empowering, we mean providing with resources, such as knowledge, finances, abilities, lobby mechanisms, exemption from rules and laws, and space for experimenting (Avelino 2007). An empowered niche may cluster with other empowered niches and emerge into a niche regime. This arises from the notion of coevolution in complexity science. Multiple regimes that co-evolve with each other: a dominant regime and one (or more) niche regime(s). Crucial is the co-evolution of a regime within the existing power structure and a niche regime outside the power realm. Co-evolving regimes influence each other in an irreversible manner, with an unknown outcome. The niche regime may take over the incumbent regime, but may also be absorbed and encapsulated by the incumbent regime.

"Anticipation and adaptation"- anticipating future trends and developments, taking account of weak signals, and seeds of change acting as the harbingers of the future - are key elements of a proactive, longterm strategy as transition management. This future orientation is accompanied by a strategy of adaptation, which means adjusting while the structure of the system is changing. This requires adequate insight into the dynamics of a complex system. Not in the sense that the future state of such a system is predictable, but there are periods when the system behaves in a relatively orderly manner and, to a limited extent, is predictable. But there are also periods in which chaos rules and the behavior of the system is quite unpredictable. So although the degree of predictability is rather small, transitions do imply generic patterns that indicate the future pathway.
The above management principles are reflexive in the sense that they interpret managing as searching, learning, and experimenting rather than command and control. They reflect a limited degree of managing transitions: not in a top-down manner but rather in a subtle way, by expediting and stimulating transition processes toward a more sustainable state. The challenge is to translate the above rather abstract management rules into a practical management framework without losing too much of the complexity involved and without becoming too prescriptive. We have attempted this by designating transition management as a cyclical process of development phases at various scale levels.

The cycle of transition management consists of the following components (Rotmans 2005, Loorbach 2007; Fig. 1):

- Problem structuring and establishment of a transition arena. An integrated systems analysis provides insight into the complexity of the system, its major defining subsystems, the dominant causal relations, feedback loops, and the roots and nature of structural problems, and forms common ground for discussing visions, strategies, and future actions. The selection of participants in a transition arena is of crucial importance: participants need to have some basic competencies at their disposal: they need to be visionaries and frontrunners, and have the ability to look beyond their own domain.

- Development of sustainability visions, pathways, and a transition agenda. Longterm visions of sustainability can function as a guide for bottom-up initiatives of frontrunners and can have a mobilizing function. Transition visions embrace multiple transition images to represent a variety of possible options and include transition goals. Various transition pathways lead to a particular transition image and from various transition images, a particular transition pathway may be derived. The transition images can be adjusted as a result of what has been learned by the players in transition experiments. The transition agenda contains both the sustainability vision, (learning) objectives, and concrete experiments. 
- Initiation and execution of transition experiments. From the transition visions and images, transition experiments can be derived that are related to existing activities. Transition experiments are high-risk experiments with a social-learning objective that are supposed to contribute to the sustainability goals at the systems level and should fit within the transition pathways. The aim is to create a portfolio of transition experiments that reinforce each other and contribute to the sustainability objectives in significant and measurable ways.

- Monitoring and evaluating the transition process. Continuous monitoring is a vital part of the search and learning process of transitions. Monitoring the transition process involves physical changes in the system in question, slowly changing macro developments, fast niche developments, seeds of change, as well as movements of individual and collective actors at the regime level. Monitoring of transition management involves the monitoring of actors within the transition arena with regard to their behavior, networking activities, and projects, and of the transition process itself with regard to the rate of progress, the barriers, and points to be improved, etc. Evaluating these monitoring aspects within each phase may stimulate a social-learning process among actors involved.

In this cycle, the "transition arena" is a key concept: a learning network that provides room for long-term reflection and prolonged experimentation. Such a transition arena has to be supported by political actors or regime powers, but not dictated by them. Within such a transition arena, each actor has to redefine his own role, competencies, and "modus operandi" in interaction and co-production with the other actors. The transition arena is meant to stimulate the formation of new coalitions, partnerships, and networks. Activities related to the content (systems analysis, envisioning, agenda building, and experiments) are linked to activities related to the process (network and coalition building, executing experiments, and process structuring). The ultimate goal of transition management is to create a societal movement through new coalitions, partnerships, and networks around arenas that allow for building up continuous pressure on the political and market arena to safeguard the long-term orientation and goals of the transition process.

The concept and framework of transition management needs to be tested more thoroughly and solidly. A range of empirical research activities has, therefore, been initiated, varying from ex-post case studies, which are historical reconstructions of transitions to ongoing case studies in which transition researchers actively participate. The most advanced example is the energy transition led by the Ministry of Economic Affairs (Kemp and Loorbach 2005). The challenge is to empirically validate the concept of transition management in such a manner that it may be claimed as a scientifically well-grounded framework to be used and further developed in a broad, international context.

\section{SOCIOMETABOLIC TRANSITIONS AND SOCIETAL TRANSITIONS: PROMISING MEETING GROUNDS BETWEEN THE TWO APPROACHES}

In the introduction, we sketched certain conceptual specifications of "transitions" to structure our two transition approaches: temporal scale and paradigm, interactions across (spatial and functional) scales, and patterns of actor/systems dynamics.

(1) On the temporal scale, we could see that the temporal grid is fairly different: whereas the sociometabolic approach refers to a time span from decades to centuries, the transition management approach focuses on periods of one or two generations. Whereas the Viennese approach documents empirically that developing countries strive after and seek to copy the historical processes of industrial transformation, and documents the transformation of an historical agrarian regime to an industrial one across several decades or even centuries, the Dutch approach focuses mainly on contemporary regional or sectoral transitions (energy, construction, water) in industrialized societies with the aim of influencing them toward a more sustainable direction, on a time scale of no more than decades. Both approaches employ a "transitions" model as a paradigm for non-linear, non-incremental change between two qualitatively different states. Thus, they share the conviction that a more linear and incremental model of "modernization" is not adequate. The temporal interface or meeting ground for the two approaches 
Fig. 1. Activity clusters in transition management.

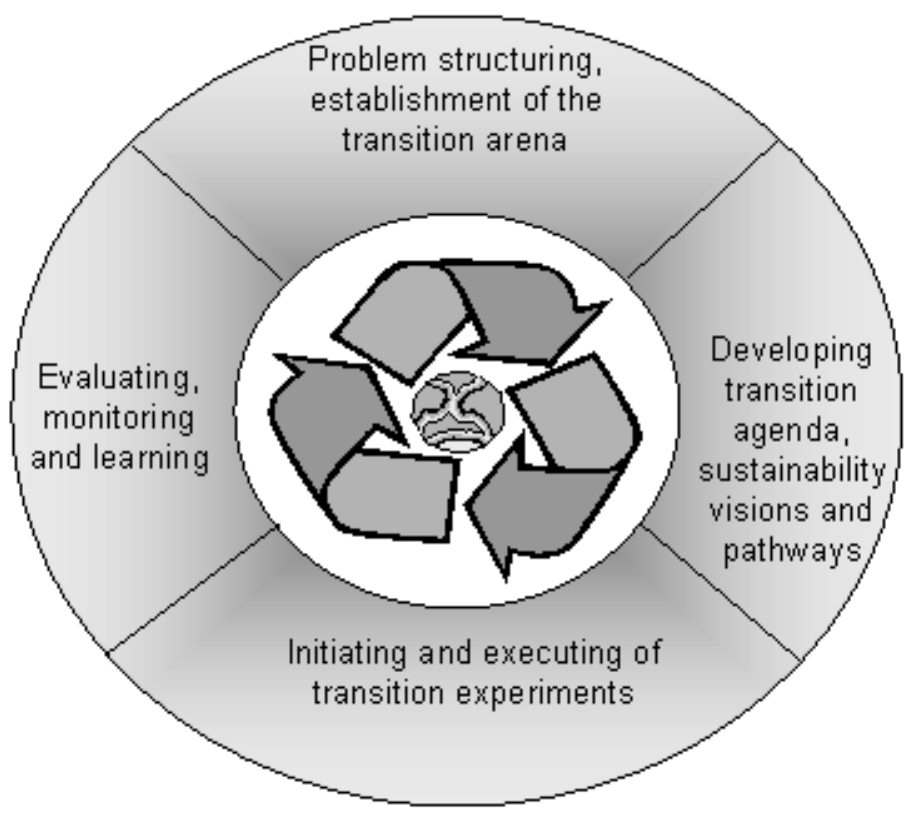

are the next two decades, in which a global strategy of preventing dangerous climate change and securing peaceful solutions for global resource scarcity, and thus a vision of global sustainability, may establish itself, or a pathway will be pursued in which the industrial countries strive mainly for their own short-term competitive advantage and create an irresistible pull for the rest of the world.

(2) If we look at the second important conceptual component of transitions, the interaction between scale levels, the Viennese approach deals with interactions across multiple scales in a fairly casespecific way, with no theoretical guidelines for the dynamics of cross-scale interactions and with a strong emphasis on the macro (landscape) level. The Dutch approach, on the other hand, systematically describes a transition as continuous interference of processes at three different scale levels: macromeso-micro. At the meso level, the notion of "regime" is pivotal, referring to a certain dominant pattern of structure, culture, and practices of the system concerned. The regime is thought to be the major stabilizing factor in the prevailing pattern, with no explicit link to some grand historical or human ecological theory. How this interference of processes across different scales actually works requires more empirical evidence and confirmation. The sociometabolic approach, on the other hand, uses the term "regime" to characterize societal modes of subsistence, that is very distinct patterns of societal metabolism and distinct strategies of colonizing natural systems, in interaction with quite different states of the relevant natural systems, on a macro level. A promising research interface between the two approaches would be the effort, on the part of the Viennese, to explore the role of niche dynamics, and the role of what the Dutch call "regimes" (on a meso level) in the time period before an actual macro transformation has taken place.

(3) As far as the underlying patterns of transition in both approaches are concerned, the Dutch approach conceptualizes a transition as arising out of a 
complex interplay between a dominant (or "incumbent") regime and a set of competing niches, where actors influence systems and vice versa. The Viennese team, on the other hand, draws a distinction between "natural" and "communication" systems and conceives of them as structurally coupled. This has not resulted yet in the formulation of common generalizations of transition patterns, but in the identification of specific drivers of historical and contemporary transitions, such as population growth and density, resource and land scarcity, climatic variations, and specific colonial and trade relations. A common meeting ground would be provided by case studies dealing with both system characteristics and actor behavior, trying to relate these two groups of variables empirically.

In many ways the two approaches rest on a conceptually similar paradigm:

- Both are systemic approaches conceiving of societies as complex systems in interaction with natural systems. Systemic change then encompasses changes in the patterns of interdependence of a broad range of variables. For the sociometabolic transitions approach, it is crucial that this also involves society-nature interactions and changes in natural systems. The transition management approach is more focused on social, economic, and cultural changes, changes that may imply a change in environmental impacts.

- Both approaches conceive of sustainability as a major deviation from current pathways, requiring substantial efforts on the part of society.

- Both approaches use the notion of coevolution, but in somewhat divergent ways.

- Both approaches build upon a nondevelopmental paradigm: the evolution of social systems occurs in a non-directional manner; there is no hierarchically preestablished order of stages. The transition to states that may be considered more sustainable is by no means an automatically built-in turn of history. Nevertheless, the purpose of the analysis is furthering sustainable development, and finding pathways toward sustainability.
Quite obviously, the two approaches are complementary rather than competing. Their complementarity derives from the difference in context of origin and key purpose: whereas one focuses mainly on analysis, the other is clearly oriented toward intervention with the goal of furthering a transition toward sustainability. But this distinction is bound to narrow down if both continue on their current research tracks. Although the Dutch approach is now strengthening its theoretical base, learning from a growing empirical portfolio of case studies (Kemp et al. 2007, Loorbach 2007), the Viennese approach is increasingly used and tried out in practical political contexts (Haas et al. 2004, Stone 2006, Gaube et al. 2009) and linking to agentbased models.

It is interesting to note that both approaches represent "schools" and thereby ways of collectively organizing research, similar to the much larger Stockholm-centered "resilience alliance" (Stockholm Resilience Centre 2008). They represent schools not only in the sense that many of the researchers use a common terminology and refer to one another, but also in the sense of long-term direct collaboration within a shared design and often organizational interdependence. Consequently, they both appear fairly selfreferential and "closed." Still, both schools are broadly interdisciplinary, but originating from a different intellectual background (sociology and history for the Viennese approach, complex systems theory, adaptive governance, and sociotechnical studies for the Dutch approach). On their paths of crossover, even if coming from different corners, they meet on broad social-science grounds, and could gain in momentum and explanatory power by increasing their mutual interlinkages as well as by further exploring interlinkages with related schools of thought and policy.

Responses to this article can be read online at: http://www.ecologyandsociety.org/voll4/iss2/art3/responses/

\section{Acknowledgments:}

This article is an outcome of a collaboration within the EU-FP-6 IP MATISSE (Methods and Tools for Integrated Sustainability Assessment). It also benefited from the Austrian National Science Fund project GLOMETRA (P 21012-911). 


\section{LITERATURE CITED}

Ayres, R. U., and A. V. Kneese. 1969. Production, consumption and externalities. American Economic Review 59(3):282-297.

Avelino, F. 2007. Power in transition. [online] URL: http://www.ksinetwork.nl.

Berkes, F., and C. Folke. 1998. Linking social and ecological systems for resilience and sustainability. Pages 1-26 in F. Berkes and C. Folke, editors. Linking social and ecological systems. Management practices and social mechanisms for building resilience. Cambridge University Press, Cambridge, UK.

Berkhout, F., A. Smith, and A. Stirling. 2004. Socio-technological regimes and transition contexts. Pages 48-75 in B. Elzen, F. W. Geels, and K. Green, editors. System innovation and the transition to sustainability: theory, evidence and policy. Edward Elgar, Cheltenham, UK.

Boserup, E. 1981. Population and technological change - a study of long-term trends. The University of Chicago Press, Chicago, Illinois, USA.

Boulding, K. E. 1970. A primer on social dynamics: history as dialectics and development. The Free Press, New York, New York, USA.

Boulding, K. E. 1973. The economics of the coming spaceship earth. Pages 3-14 in H. E. Daly, editors. Towards a steady state economy. Freeman, San Francisco, California, USA.

Boyden, S. V. 1992. Biohistory: the interplay between human society and the biosphere-past and present. UNESCO and Parthenon Publishing Group, Paris, Casterton Hall, Park Ridge, New Jersey, USA.

de Haan, H., and J. Rotmans. 2007. A theoretical framework for understanding the dynamics of societal transitions. Working paper. DRIFT, Rotterdam, The Netherlands.

Diamond, J. 1997. Guns, germs, and steel: the fates of human societies. W. W. Norton and Company, New York, New York, USA and London, UK.

Engels, F. 1968. The part played by labour in the transition from ape to man. Socialist Appeal
Publications, London, UK.

Eurostat. 2005. Development of material use in EU 15 states 1970-2001. Eurostat, Luxembourg.

Fischer-Kowalski, M., and H. Haberl. 1997. Stoffwechsel und Kolonisierung: Konzepte zur Beschreibung des Verhältnisses von Gesellschaft und Natur. Pages 3-12 in M. Fischer-Kowalski, H. Haberl, W. Hüttler, H. Payer, H. Schandl, V. Winiwarter, and H. Zangerl-Weisz, editors. Gesellschaftlicher Stoffwechsel und Kolonisierung von Natur. Gordon and Breach Fakultas, Amsterdam, The Netherlands.

Fischer-Kowalski, M., and H. Haberl. 2007. Socioecological transitions and global change. Edward Elgar, Cheltenham, UK.

Fischer-Kowalski, M., H. Haberl, and F. Krausmann. Conclusions: likely and unlikely pasts, possible and impossible futures. Pages 223256 in M. Fischer-Kowalski and H. Haberl. Socioecological transitions and global change. Edward Elgar, Cheltenham, UK.

Fischer-Kowalski, M., and H. Weisz. 1999. Society as hybrid between material and symbolic realms. Toward a theoretical framework of societynature interaction. Advances in Human Ecology 8:215-251.

Foster, J. B. 2000. Marx's ecology. Materialism and nature. Monthly Review Press, New York, New York, USA.

Gaube, V., C. Kaiser, M. Wildenberg, H. Adensam, P. Fleissner, J. Kobler, J. Lutz, A. Schaumberger, J. Schaumberger, B. Smetschka, A. Wolf, A. Richter, and H. Haberl. 2009. Combining agent-based and stock-flow modelling approaches in a participative analysis of the integrated land system in Reichraming, Austria. Landscape Ecology, in press.

Geels. F. W. 2002. Understanding the dynamics of technological transitions: a co-evolutionary and socio-technical analysis. Dissertation, Twente University Press, Enschede, The Netherlands.

Geels, F. W. 2005. The dynamics of transitions in socio-technical systems: a multi-level analysis of the transition pathway from horse-drawn carriages to automobiles (1860-1930). Technology Analysis and Strategic Management 17(4):445-476. 
Geels, F. W., and J. Schot. 2007. Typology of transition pathways in sociotechnical systems. Research Policy 36(3):399-417.

Gellner, E. 1988. Plough, sword and book. Collins Harvill, London, UK.

Gersick, C. J. G. 1991. Revolutionary change theories: a multi-level exploration of the punctuated equilibrium paradigm. The Academy of Management Review 16 (1):10-36.

Godelier, M. 1986. The mental and the material: thought economy and society. Blackwell Verso, London, UK.

Goudsblom, J., E. Jones, and S. Mennell. 1996. The course of human history. economic growth, social process, and civilization. M. E. Sharpe, Armonk, New York, USA and London, UK.

Gould, S. J., and N. Eldredge. 1977. Punctuated equilibria: the tempo and mode of evolution reconsidered. Paleobiology 3:115-151.

Gunderson, L. H., and C. S. Holling. 2002. Understanding transformations in human and natural systems. Island Press, Washington, D.C., USA.

Haas, W., C. M. Grünbühel, and H. Haberl. 2004. Flood-induced changes in socio-economic metabolism. A local case study of flood impacts on society. Pages 53-64. in R. Jandl, H. Hager, W. Loiskandl, M. Gerzabeck, H. Mauser, O. Moog, and H. Richter, editors. Water and society, needs, challenges and restrictions. Proceedings, International conference held at the University of Natural Resources, and Applied Life Sciences, Vienna, 19-21 November 2003. Universität für Bodenkultur, Vienna, Austria.

Haberl, H. 2001. The energetic metabolism of societies, part i: accounting concepts. Journal of Industrial Ecology 5(1):11-33.

Haberl, H., S. P. J. Batterbury, and E. F. Moran. 2001. Using and shaping the land: a long-term perspective. Land Use Policy 18(1):1-8.

Haberl, H., M. Fischer-Kowalski, F. Krausmann, H. Weisz, and V. Winiwarter. 2004. Progress towards sustainability? What the conceptual framework of material and energy flow accounting (MEFA) can offer. Land Use Policy 21(3):199-213.
Haberl, H., K. H. Erb, F. Krausmann, V. Gaube, A. Bondeau, C. Plutzar, S. Gingrich, W. Lucht, and M. Fischer-Kowalski. 2007. Quantifying and mapping the human appropriation of net primary production in earth's terrestrial ecosystems. Proceedings of the National Academy of Sciences of the United States of America 104:12942-12947.

Holling, C. S. 1973. Resilience and stability of ecological systems. Annual Review of Ecological Systematics 4:1-24

Kemp, R., and D. Loorbach. 2005. Dutch policies to manage the transition to sustainable energy. Pages 123-151 in Jahrbuch Okologische Okonomik. Metropolis Verlag, Marburg, Germany.

Kemp, R., J. Rotmans, and D. Loorbach. 2007. Assessing the Dutch energy transition policy: how does it deal with dilemmas of managing transitions, Journal of Environmental Policy and Planning 9(34):315-331.

Kern, F., and A. Smith. 2007. Restructuring energy systems for sustainability? Energy transition policy in the Netherlands. Sussex Energy Working Paper, SPRU, University of Sussex, Brighton, UK.

Krausmann, F., M. Fischer-Kowalski, M., N. Eisenmenger, and H. Schandl. 2008. The global socio-metabolic transition. Past and present metabolic profiles and their future trajectories. Journal of Industrial Ecology. 12(5/6):637-656.

Krausmann, F., and H. Haberl. 2002. The process of industrialization from the perspective of energetic metabolism. Socioeconomic energy flows in Austria 1830-1995. Ecological Economics 41 (2):177-201.

Loorbach, D. 2007. Transition management: new mode of governance for sustainable development. International Books, Utrecht, The Netherlands.

Loorbach, D., and J. Rotmans. 2006. Managing transitions for sustainable development. Pages 187206 in S. Oslthoorn and A. Wieczorek. Understanding industrial transformation: views from different disciplines. Springer, Dordrecht, The Netherlands.

Luhmann, N. 1995. Social systems. Stanford University Press, Palo Alto, California, USA. 
Marx, K. 1976. Capital. Volume 1. Vintage, New York, New York, USA. (Originally published 1867.)

McNeill, J. R. 2000. Something new under the sun. An environmental history of the twentieth century. Allen Lane, London, UK.

Meyer, W. B., and B. L. I. Turner. 1994. Changes in land use and land cover, a global perspective. Cambridge University Press, Cambridge, UK.

Ministry of Housing, Spatial Planning and Environment (VROM). 2001. National environmental policy plan: when there is a will there is a world. VROM, The Hague, The Netherlands.

Mitleton-Kelly, E. 2003. Ten principles of complexity and enabling infrastructures. Pages 319 in E. Mitleton-Kelly, editor. Complex systems and evolutionary perspectives of organizations: the application of complexity theory to organizations. Elsevier, London, UK.

Prigogine, I., and I. Stengers. 1984. Order out of chaos: man's new dialogue with nature. New Science Library, Boulder, Colorado, USA.

Rappaport, R. A. 1971. The flow of energy in an agricultural society. Scientific American $\mathbf{2 2 5}$ (3):116-136.

Rip, A., and R. Kemp. 1998. Technological change. Pages 327-399 in S. Rayner and E. L. Malone, editors. Human choice and climate change: an international assessment. Volume 2. Batelle Press, Washington, D.C., USA.

Rittel, H., and M. Webber. 1973. Dilemmas in general theory of planning. Policy Sciences 4 (2):155-159.

Rotmans, J. 2005. Societal innovation: between dream and reality lies complexity. Inaugural speech, Rotterdam School of Management, ERIM, Erasmus University, Rotterdam, The Netherlands.

Rotmans, J., R. Kemp, and M. B. A. van Asselt. 2001. More evolution than revolution: transition management in public policy. Foresight 3(1):1532.

Rotmans, J., and D. Loorbach. 2008. Transition management: reflexive governance of societal complexity through searching, learning and experimenting, Pages 15-46 in J. van den Bergh and $\mathrm{F}$. Bruinsma. Managing the transition to renewable energy. Edward Elgar, Cheltenham, UK.

Schandl, H., and N. Eisenmenger. 2006. Regional patterns in global resource extraction. Journal of Industrial Ecology 10(4):133-147.

Schellnhuber, H. J. 1999. Earth system analysis and the second Copernican revolution. Nature $\mathbf{4 0 2}$ (Suppl.):C19-C23.

Sieferle, R. P. 1997. Rückblick auf die Natur: Eine Geschichte des Menschen und seiner Umwelt. Luchterhand, Munich, Germany.

Sieferle, R. P. 2003. Sustainability in a world history perspective. Pages 123-142 in B. Benzing, editor. Exploitation and overexploitation in societies past and present. IUAES-Intercongress 2001 Goettingen. LIT Publishing House, Münster, Germany.

Sieferle, R. P., F. Krausmann, H. Schandl, and V. Winiwarter. 2006. Das Ende der Fläche. Zum Sozialen Metabolismus der Industrialisierung. Böhlau, Cologne, Germany.

Smith, A., and F. Kern. 2007. The transitions discourse in the ecological modernization of the Netherlands. SPRU Electronic Working Paper Series no. 160. University of Sussex, Brighton, UK.

Smith, A., A. Stirling, and F. Berkhout. 2005. The governance of sustainable socio-technical transitions. Research Policy 34:1491-1510.

Spencer, H. 1876. The principles of sociology. Williams and Norgate, London, UK.

Stockholm Resilience Centre. 2008. Annual report 2007. Stockholm University, Stockholm, Sweden.

Stone, R. 2006. Simron Singh profile: after the tsunami: a scientist's dilemma. Science $\mathbf{3 1 3}$ (5783):32-35.

Turner, B. L. I., W. C. Clark, R. W. Kates, J. F. Richards, J. T. Mathews, and W. B. Meyer. 1990. The earth as transformed by human action: global and regional changes in the biosphere over the past 300 years. Cambridge University Press, Cambridge, UK. 
Vitousek, P. M. 1992. Global environmental change: an introduction. Annual Review of Ecology and Systematics 23:1-14.

Vitousek, P. M., P. R. Ehrlich, A. H. Ehrlich, and P. A. Matson. 1986. Human appropriation of the products of photosynthesis. BioScience 36(6):363373.

Weisz, H., F. Krausmann, C. Amann, N. Eisenmenger, K.-H. Erb, K. Hubacek, and M. Fischer-Kowalski. 2006. The physical economy of the European Union: cross-country comparison and determinants of material consumption. Ecological Economics 58(4):676-698.

White, L. A. 1943. Energy and the evolution of culture. American Anthropologist 45(3):335-356. 